\title{
Schools' Flood Emergency Preparedness in Khyber Pakhtunkhwa Province, Pakistan
}

\author{
Ashfaq Ahmad Shah ${ }^{1} \cdot J_{\text {Jingzhong } \mathrm{Ye}^{1} \cdot \text { Lu Pan }^{1} \cdot \text { Raza Ullah }^{2} \cdot \text { Syed Irshad Ali Shah }}{ }^{3} \cdot$ \\ Shah Fahad $^{4} \cdot$ Shaista $\mathrm{Naz}^{5}$
}

Published online: 7 June 2018

(C) The Author(s) 2018

\begin{abstract}
Pakistan is highly exposed to climate-induced disasters, especially floods. Flooding history shows that educational establishments have been disproportionately hard-hit by flooding events. In Pakistan, school safety and preparedness is still a choice, rather than a mandatory requirement for all schools. But schools in Pakistan do have a responsibility to keep safe the students in their care, especially during and after the catastrophic events. This implies the need to maintain the environment in and around school property, so as to minimize the impacts of floods and to have the mechanisms in place to maximize a school's resilience. This study examined the emergency preparedness activities of 20 schools in four districts of Khyber Pakhtunkhwa Province that had recently been severely affected by floods. Through face to face interviews and a structured questionnaire $(n=100)$ we collected data on the four pillars of emergency preparedness: emergency planning, preparation measures, safe school facilities, and hazard education and training. The study revealed that the majority of the sample schools had
\end{abstract}

Jingzhong Ye

yejz@cau.edu.cn

1 College of Humanities and Development Studies (COHD), China Agriculture University, Beijing 100083, China

2 Institute of Agriculture and Resource Economics, University of Agriculture, Faisalabad 38000, Pakistan

3 Department of Agricultural Economics and Management, Zhejiang University, Hangzhou 310058, China

4 College of Economics and Management, Northwest A\&F University, Yangling 712100, China

5 Institute of Development Studies (IDS), The University of Agriculture Peshawar (AUP), Peshawar, Khyber Pakhtunkhwa 25000, Pakistan experienced more than one natural hazard-induced disaster, predominantly flooding, yet despite this had not undertaken adequate emergency preparedness activities. There are particular gaps with regard to plans for students with disabilities, the continuity of school operations after a disaster, the presence of maps to identify evacuation routes, the availability of emergency equipment and resources, disaster preparedness guidelines, and psychological first aid and crisis counseling. The strengths, weaknesses, opportunities, and threats analysis that our researchers carried out indicates that, although schools in the survey have taken many steps towards flood preparedness, many weaknesses still exist and there remain significant opportunities to strengthen the preparedness level of many schools. The goal of this study is to inform policy decisions that improve school safety in Pakistan and to suggest the priority areas for future school disaster preparedness and management efforts.

Keywords Emergency preparedness - Flood disaster · Pakistan - School resilience $\cdot$ School safety culture

\section{Introduction}

Education plays a crucial role in shaping the future of a country. It gives future citizens "capacity," contributes to sustainable development and promotes human security (Shaw et al. 2011). A strong and safe educational environment contributes greatly to the physical and mental well-being of children and provides a foundation for them to become active agents within society. If educational continuity is interrupted as a result of natural hazards, children can easily drop out of the educational system and 
are more likely to be illiterate when they leave school, thereby harming the country's (and their own) economic prospects and health. Governments have a responsibility to ensure basic education for all including children, which some citizens take more seriously than others. It is estimated that children spend $35-40 \%$ of their time at school and this means that it is worth examining the safety (or vulnerability) of children in the face of possible disasters during this time. It is important, as the Asian Disaster Preparedness Center noted (ADPC 2010), to ask whether schools promote a safety culture that protects children from disasters. Although much research has been carried out on the "safety culture" concept (Zohar 1980; Brown and Holmes 1986; Lutness 1987; Dedobbeleer and Béland 1991; Ostrom et al. 1993; Geller 1994; Coyle et al. 1995; Lee 1996; Williamson et al. 1997), the concept itself remains poorly-defined (Guldenmund 2000). Safety culture is often used to define the way safety is managed and often reveals people's attitudes and perceptions about safety (Cox and Cox 1991). It also reflects the factors that shape the environment within which individual attitudes towards safety are developed, and safety-enhancing behavior is promoted. Based on the literature cited above, we can define safety culture as the specific measures taken by individuals or groups of people to ensure their safety from disasters. This culture of safety is relevant to the catastrophic impact of disasters in the education sector. Schools can play a catalytical role in promoting a culture of safety that bridges communities and institutions and helps them better deal with future risks (ADPC 2010).

It is evident from historical data about disasters that children are one of the most vulnerable groups in society, and are more prone to become the victims of natural hazard-induced disasters, particularly while attending school (UNISDR 2007). The World Health Organization (WHO 2011) estimated that $30-50 \%$ of the total fatalities from natural hazard events are children. Not only are they more vulnerable and likely to be harmed, they also have less access to humanitarian aid (food and health care), and are exposed to other risks, including separation from their parents or guardians (Peek 2008). Exposure to disasters can lead children to become depressed, suffer emotional stress, and provoke behavioral problems (Newman et al. 2014; Masten et al. 2015). Natural hazard-induced disasters can also damage the infrastructure of school buildings, which stalls children's access to education. For instance, in 2005 the deadliest earthquake on record killed 1600 school children in Pakistan, and over 200 students were buried alive in the Philippine s by a mudslide (Mamogale 2011). This illustrates the importance of protecting children from disaster risks, which can be done through two mechanisms: disaster risk education, and ensuring school safety (Wisner 2006).
The school safety framework of Sakurai and Shaw (2015) provides a structure that can significantly enhance school safety, strengthen disaster risk education, identify priorities for enhancing student's safety at school, and ensure continued access to primary education for children following a catastrophic disaster. Each element of the framework contains a set of preparedness activities (for example, retrofitting buildings, developing emergency plans, and integrating disaster education into the curriculum) to ensure student's safety prior to, and following, disasters (Tipler et al. 2017). Schools also play a significant role within their communities by connecting children and families (Ronan and Johnston 2005). The role of education providers is to provide a safe learning environment (Peek 2008), which involves the protection of students from disasters while they are at school (Wisner 2006), assistance for students and their families to recover from the social, psychological, and physical traumas that may arise as a result of disasters (Mamogale 2011), and provision of a stable environment in which to reestablish their routines (Peek 2008). Chung et al. (2009) stress the importance of establishing emergency plans to safeguard student safety, and family reunification procedures that ensure that students are returned safely to their parents in an emergency situation (Graham et al. 2006).

Pakistan $\left(23.35-37.50^{\circ} \mathrm{N}\right.$ and $\left.60.50-77.50^{\circ} \mathrm{E}\right)$ covers an 881,913 square kilometer area, ${ }^{1}$ has a population of just under 210 million people, ${ }^{2}$ which makes Pakistan the fifth most populous country in the world, and is a near neighbor to Iran, Afghanistan, China, and India. With an extensive coastline that gives access to the Arabian sea, the country has three main geographic regions: the Indus River plain to the east, The Baluchistan Plateau in the center, and the mountainous north (Karakoram), which contains the world's second highest mountain (K2). ${ }^{3}$ Over the past two decades, the country has been severely affected by a series of disasters, often climate-related, including 16 serious widespread floods (Shah et al. 2017, 2018; Fahad and Wang 2018). The 2010 flood was the worst (Fahad et al. 2018), affected 78 districts, damaged agricultural crops over more than 2 million hectares, and partially or completely destroying more than 10 thousand educational structures (ADB and WB 2010). The cost of the tragedy was estimated at over USD 10 billion (Shah et al. 2017). Of the 10,348 educational institutions affected by the flood, 9368 were primary schools (Khan and Ali 2014). In many instances local communities looked to school buildings and infrastructure to provide them with emergency shelter when their houses were destroyed by a flood. The majority

\footnotetext{
${ }^{1}$ https://www.worldatlas.com/as/pk/where-is-pakistan.html.

${ }^{2}$ http://www.pbscensus.gov.pk/.

${ }^{3}$ https://en.wikipedia.org/wiki/Pakistan\#cite_note-17.
} 
of schools lacked effective coordination, and as a result students and teaching staff were severely impacted by poorly organized evacuation efforts. Advanced emergency preparedness and school safety plans would have decreased the loss of lives and injuries and the general disruption that ensued. The government of Khyber Pakhtunkhwa has undertaken a program of school safety trainings since the 2010 flood as a measure to increase the disaster preparedness level of students and teachers and has made such training mandatory throughout schools in the province (McBride 2017).

A large body of literature (MacNeil and Topping 2009; Zantal-Wiener and Horwood 2010; Momani and Salmi 2012; Brown et al. 2014; Elangovan and Kasi 2015; Johnston et al. 2016; Shiwaku et al. 2016) is available on what schools need to do to cope with disaster risks. But there is a dearth of literature that assesses the nature and levels of emergency preparedness efforts in schools. The majority of these studies have been conducted in the United States, although other studies from the UK and Europe (MacNeil and Topping 2009; Zantal-Wiener and Horwood 2010), Australia (Brown et al. 2014; Johnston et al. 2016), the Middle East (Hosseini and Izadkhah 2006; Momani and Salmi 2012), and Asia (Elangovan and Kasi 2015; Shiwaku et al. 2016) have developed an international perspective on school emergency readiness. This international concensus shifts the center of attention from school preparedness at the state level towards gathering data from individual schools, which more accurately reflects the actual levels of preparedness (Kano et al. 2007; Ramirez et al. 2009). The literature identifies some common weaknesses in emergency preparedness at the school level: limited emergency plans (US Government Accountability Office 2007; Brown et al. 2014); infrequent evaluation of preparedness plans (Hosseini and Izadkhah 2006; Johnson et al. 2014); and weak collaboration between schools and other key stakeholders (Alba and Gable 2012; Awofisayo et al. 2013). This raises questions about the capacity of schools to efficiently deal with flood and other emergencies and to ensure child safety in schools.

Pakistan has attempted initiatives to improve safety measures in schools and their preparedness for disasters through capacity building of the teachers, planning, and awareness raising. So far, these measures are inadequate and are done voluntarily rather than being mandatory for every school. This study examines whether schools in Khyber Pakhtunkhwa are suitably prepared to protect their students in flood and other emergencies, and identifies the gaps and weaknesses in existing preparedness practices. This information can be used as a basis for formulating policies for future school-based emergency management efforts. The research addresses three questions: (1) What kind of natural hazard-induced disasters have schools already experienced? (2) What preparedness measures have been taken by schools? and (3) What are the strengths, weaknesses, opportunities, and threats of existing emergency preparedness plans within the sample of schools.

\section{Research Methodology}

The purpose of this section is to outline the methods used for this research. This section deals with selection of the study area, sampling procedure, sample size, data collection methods, and analysis of the data. The details of the materials that are used to reach the final conclusion are explained below.

\subsection{Study Area and Sampling Method}

This study was conducted in Pakistan's Khyber Pakhtunkhwa Province (Fig. 1). This province was chosen due to the frequent occurrence of various hydrometeorological disasters, including floods, and the high proportion of people who are at high risk of, and vulnerable to, disaster risks due to a lack of resilient structure (school buildings and infrastructure), poorly maintained technical facilities, untrained staff, and unprofessional rescue operations. Educational establishments were particularly hard-hit in these flood events. In Khyber Pakhtunkhwa Province, 5.6\% of educational facilities were damaged (Khan and Ali 2014) with 737 primary schools destroyed (197 completely) and a total estimated damage of 2859.5 million Pakistani Rupees (PKR), approximately USD 28.6 million and more than $10 \%$ of the national total (ADB and WB 2010). Reconstruction of these facilities has been slow and partial, owing to a lack of funds, knowledge, clear policy guidelines, such as criteria for selecting future school sites. Other attributes, such as a lack of preparedness in terms of evacuation plans, designated evacuation areas, and safety awareness (UNESCO 2012), have further impacted the pace of rehabilitation.

\subsection{Sampling Procedure and Data Collection and Analysis}

This study was carried out in August and September 2017. The quantitative questionnaire was designed and pretested in the field, and an amended version of the questionnaire was subsequently shared with the Director of Elementary and Secondary Education in Khyber Pakhtunkhwa for his expert opinion, authorization, and feedback. The questionnaire included a dichotomous set of questions to assess the existing emergency preparedness in Khyber Pakhtunkhwa's primary schools (years $0-5$ ). The study adopted 


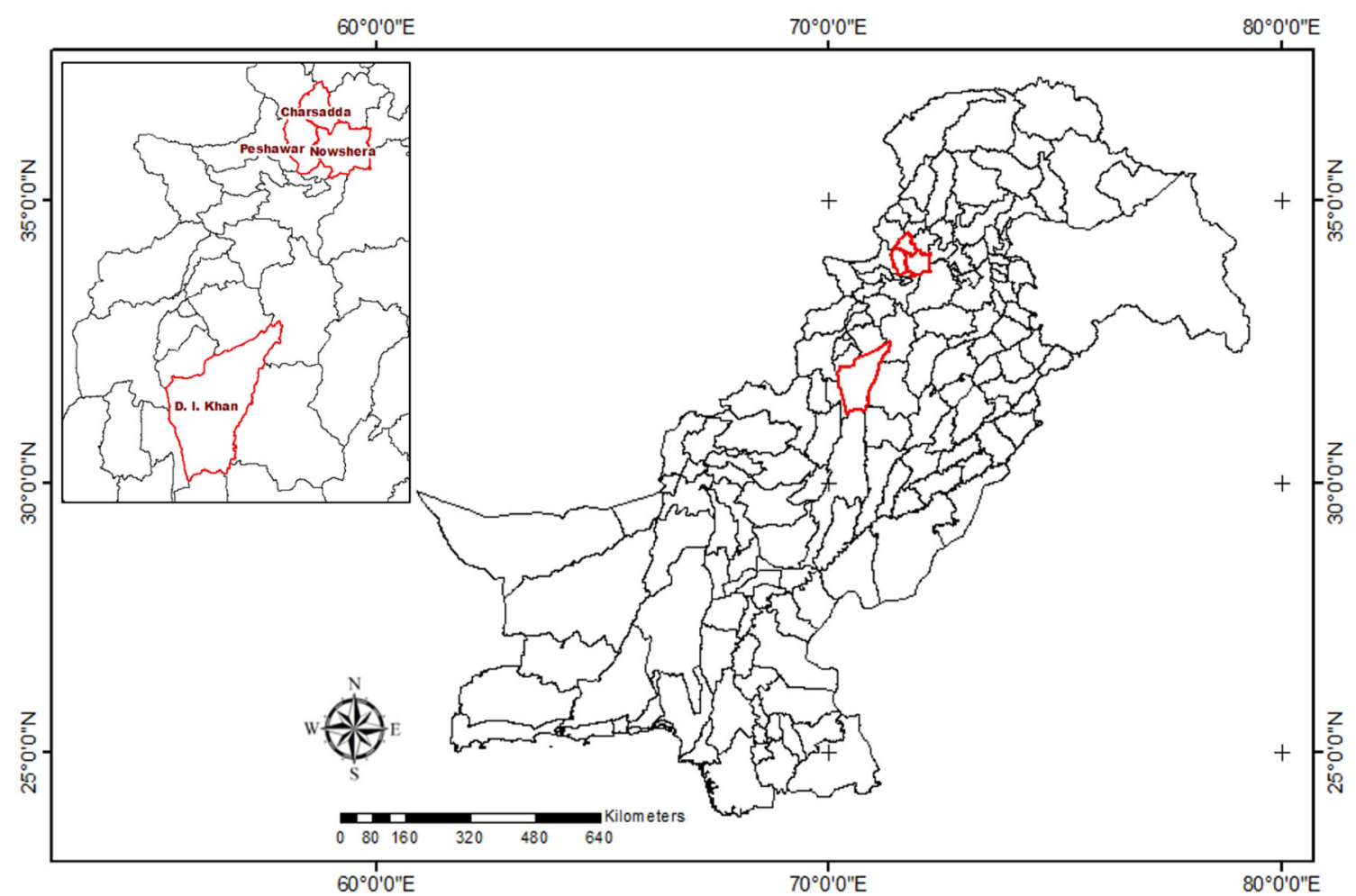

Fig. 1 Sample study districts in Khyber Pakhtunkhwa Province, Pakistan

a multistage sampling technique to select the schools and sample respondents. After selecting Khyber Pakhtunkhwa Province as the study area, purposive sampling was used to select four districts (Nowshera, Charsadda, Peshawar, and Dera Ismail, Fig. 1) out of the 24 districts that were severely affected by the 2010 flood. In the third stage, five schools were randomly selected from each district from a list of severely affected schools provided by the region's district education officers. In the last stage of sampling, five respondents were randomly selected from each school by using an updated list of school management staff that was also provided by the relevant district education officers, and yielded 25 respondents from each district. We investigated the four pillars of emergency preparedness and the responses were analyzed using SPSS (version 16). The four emergency preparedness pillars are: (1) emergency planning (Fig. 3) that consists of seven activities; (2) preparation measures (Fig. 4) that cover eight activities; (3) school safety facilities (15 activities) (Figs. 5, 6); and (4) hazard education and training that focus on four main activities (Fig. 7). A SWOT analysis was carried out for an in-depth assessment of the internal factors (strengths and weaknesses), and external factors (opportunities and threats) influencing the disaster preparedness of individual schools.

\section{Results}

It is imperative to ensure that schools in disaster-prone regions are well prepared to effectively and efficiently respond to any natural hazard-induced disasters that they might experience. The main purpose of an effective emergency response is to maintain a steady state of emergency preparedness in the event of any crisis situation (Kano and Bourque 2007). This requires the establishment of standard operating procedures, the predisaster preparation of response measures, and the development of disasterpreparedness education programs for students and teaching staff. This study provides insights into the preparedness of Khyber Pakhtunkhwa schools, seven years after the catastrophic flood disaster of 2010.

\subsection{Natural Hazard-Induced Disasters Experienced by the Khyber Pakhtunkhwa Schools}

School authorities and the schools' staff are the main stakeholders who carry the main burden of responsibility for disaster preparedness. School teachers were asked about different sources of risks in order to gauge: (1) their level of understanding of risks and their consequences; (2) whether they have any mitigation or coping strategies in place; and (3) their level of preparedness. Risk exposure remained high because these schools were still located in 
flood-prone districts and the regional governments had not found the resources to put adequate preventive measures in place. The survey revealed that more than $90 \%$ of the sample schools experienced at least one disaster between 2010 and 2012 (Fig. 2), led by 94\% of schools in Nowshera, $93 \%$ in Charsadda, $90 \%$ in Peshawar, and $88 \%$ in Dera Ismail Khan. Other disasters experienced by primary schools in our sample were landslides (1.5\%), earthquakes $(5.5 \%)$, and cyclones $(1.25 \%)$.

\subsection{Emergency Preparedness Activities Carried out in Khyber Pakhtunkhwa's Schools}

The results presented in this section provide an overall picture of the emergency preparedness activities carried out in Khyber Pakhtunkhwa's schools under the four preparedness pillars-emergency planning, preparation measures, safe school facilities, and hazard education and training. A detailed explanation is given in the following subsections.

\subsubsection{Emergency Planning}

Our study revealed that preparedness efforts in terms of emergency planning varied enormously in the four sampled districts (Fig. 3). Overall, 40\% of the sampled schools had an emergency plan for flood disaster, with schools in Dera Ismail Khan (24\%) and Peshawar (32\%) falling well below this due to the lack of awareness and knowledge about preparedness efforts compared with the school's in Nowshera and Charsadda districts. Secondly, Nowshera and Charsadda are more vulnerable to flood disasters. On average, 54\% of schools had teaching staff with specialized roles and responsibilities during emergency situations, although again these figures were lower in Dera Ismail Khan (36\%) and Peshawar (44\%). In order to measure the awareness level of staff about risk and to assess their preparedness to remain in the schools during and after a disaster, we developed a set of qualitative questions related to: (1) staff knowledge about preparedness and mitigation; (2) their knowledge about how to protect themselves and the students in their care; and (3) their knowledge concerning their general responsibility to the community during and after a disasters. The responses were converted into transformed values using a composite index that was then used to assign the value 1 to the variable when the score was more than 0.5 , and 0 if it was less than this. Figure 3 shows that $55 \%$ of staff, including teachers and administrative staff, were aware who would need to remain at the school in order to support and supervise students in case of a flood disaster. Other indicators related to emergency planning showed that $35 \%$ of the sampled schools had emergency communication plans, $23 \%$ had appropriate and inclusive plans for students, and $31 \%$ reported that they had plans for the continuity of school operations following an emergency. The development of evacuation routes and location maps was found to be very low (26\%) in the four districts, particularly in Dera Ismail Khan and Peshawar.

\subsubsection{Preparation Measures}

The eight preparation measures are measures that can reduce potential loss of life, injuries, and damage to property and support relief efforts after a flood disaster. The result is shown in Fig. 4. It shows that only $32 \%$ of the sampled schools had emergency exit signage and kept evacuation routes clear in case of emergency. An almost equally small proportion of schools (34\%) kept, and

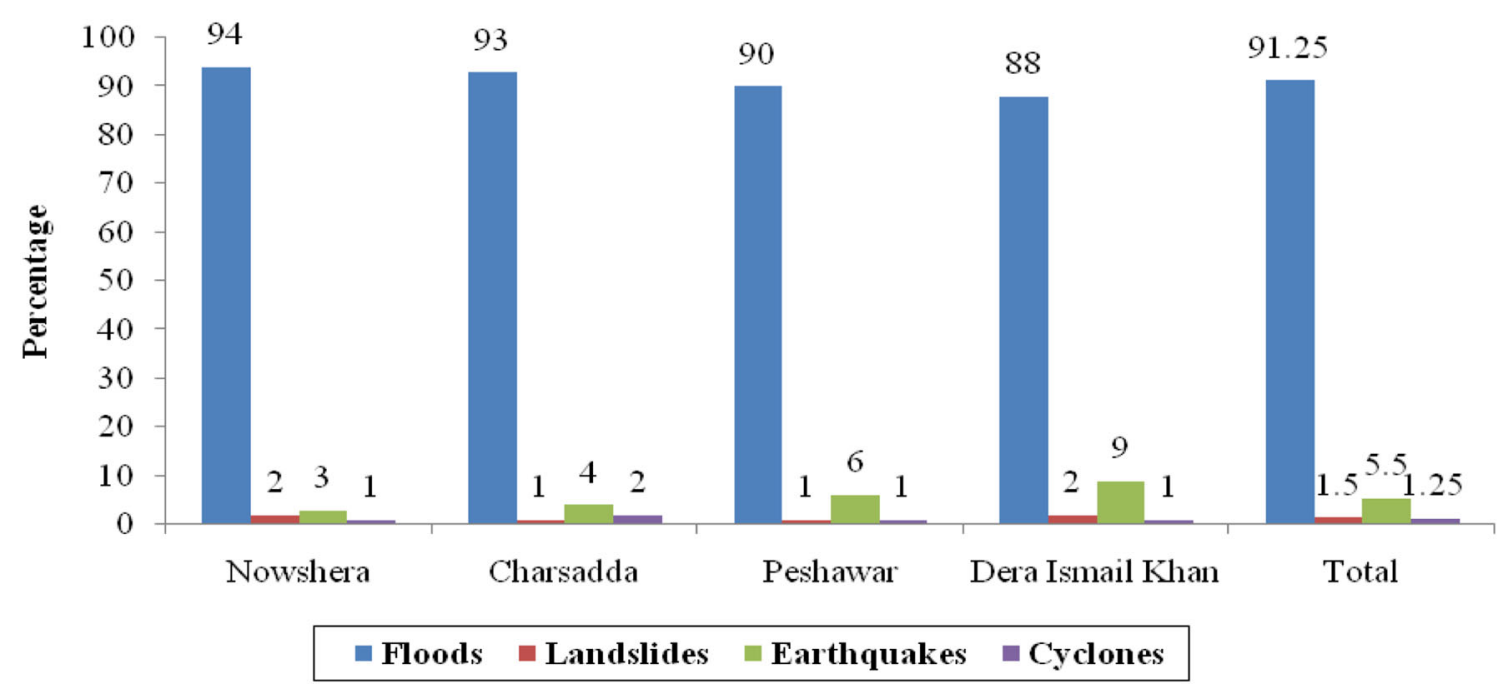

Fig. 2 Floods and other natural hazard-induced disasters experienced by Khyber Pakhtunkhwa's schools, 2010-2012 


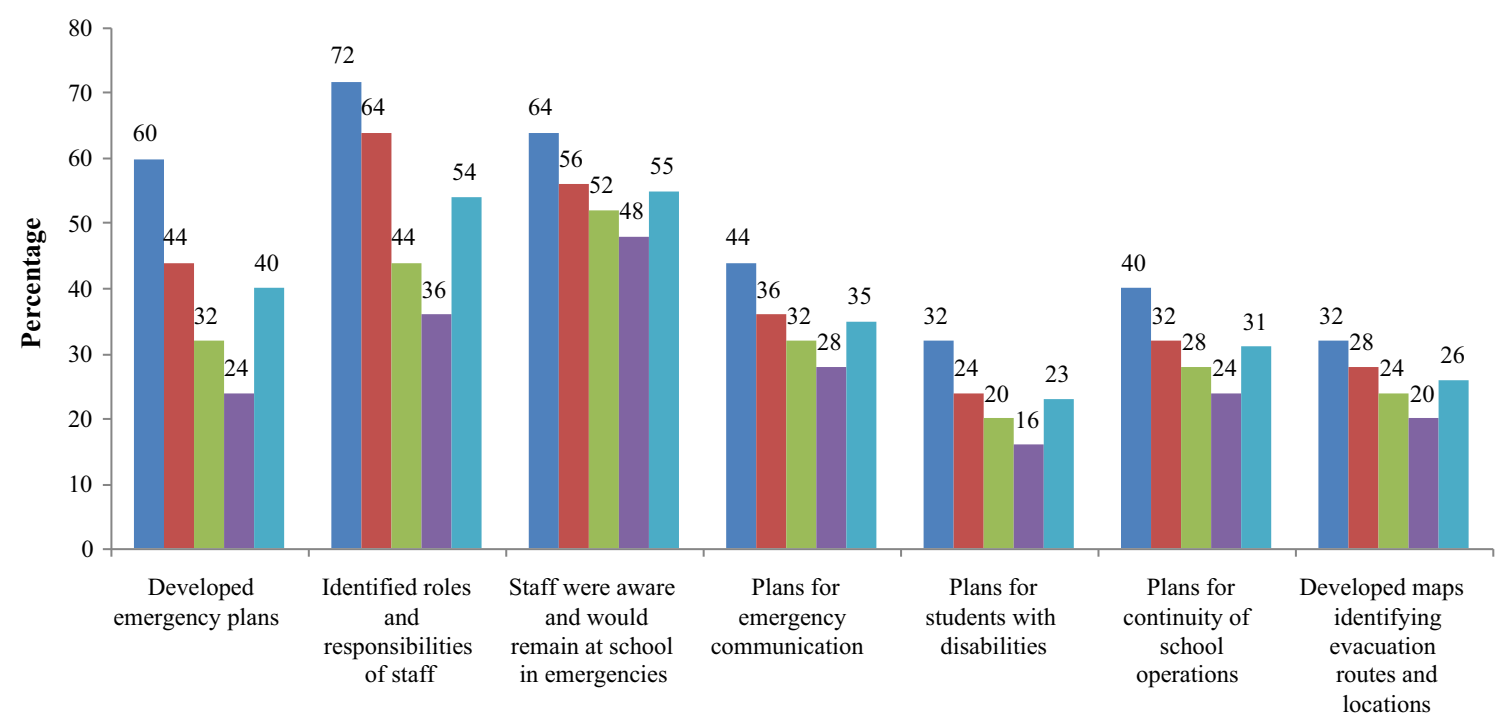

nowshera $\quad$ Charsadda $\quad$ Peshawar $\square$ D.I.Khan $\quad$ Average

Fig. 3 Emergency planning and preparedness activities of Khyber Pakhtunkhwa's schools, 2010-2017

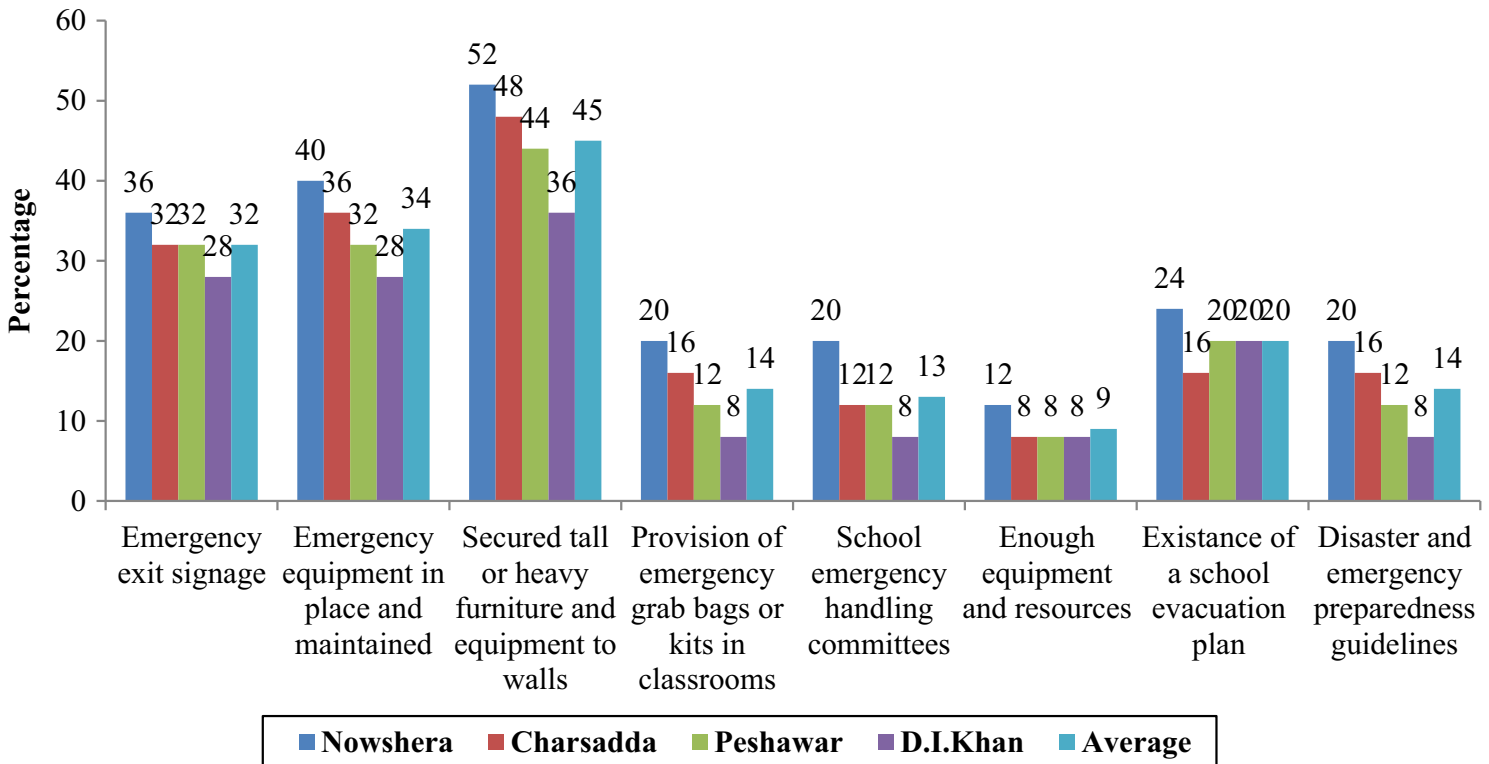

Fig. 4 Preparation measures adopted and in place in Khyber Pakhtunkhwa's schools, 2010-2017

regularly maintained, emergency equipment, while $45 \%$ had secured and fixed their tall and heavy, equipment (furniture, and so on) for safety reasons. For the other indicators the results were even more worrying: only $20 \%$ had a school evacuation plan; $14 \%$ of schools provided emergency grab bags or kits ${ }^{4}$ to their students; $14 \%$ had

\footnotetext{
${ }^{4}$ Emergency kits or grab bags are very crucial in risk management and crisis response and contain important items such as first aid kit and medication, toiletries and sanitary supplies, infant supplies, spare clothes, a battery torch with spare batteries or a wind up torch, bottled water and emergency food, enough for 3 days, and child care supplies or other special care items.
}

disaster management committees and standard emergency preparedness guidelines; and just $9 \%$ reported having sufficient equipment and resources. Once again these averages were almost universally lower in Dera Ismail Khan and Peshawar Districts.

\subsubsection{Safe School Facilities}

The third pillar of a comprehensive school safety plan covers safe school facilities, which involves different stakeholders (education authorities, construction engineers, and school community members) working together to 


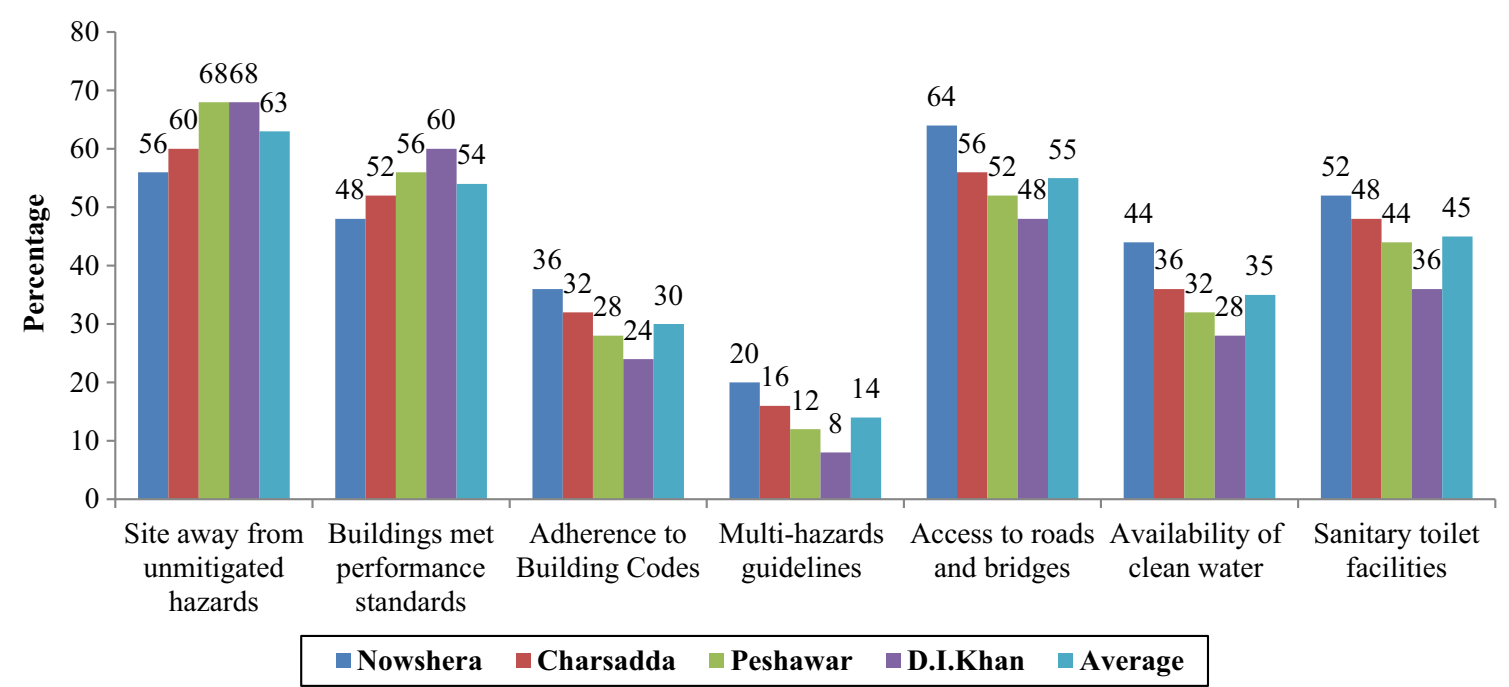

Fig. 5 School sites and building design for safety of Khyber Pakhtunkhwa's schools, 2010-2017

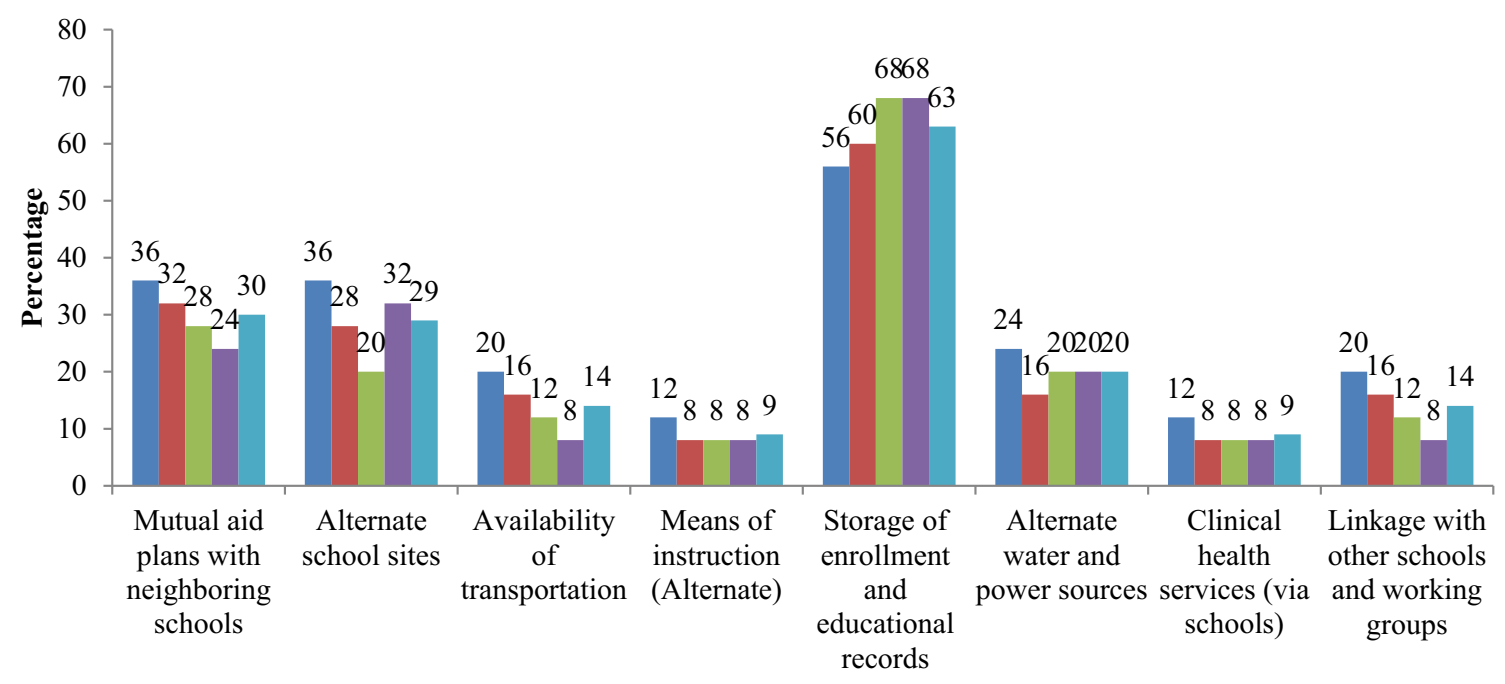

nowshera ${ }^{\text {Charsadda }}$ Peshawar D.I.Khan ${ }^{\text {Average }}$

Fig. 6 Khyber Pakhtunkhwa's school planning for continuation of teaching after a disaster, 2010-2017

ensure that school sites and buildings are safe and that continuity plans are in place (Fig. 5). The survey findings revealed that the majority (63\%) of the schools were located away from unmitigated hazards, which increased the safety of school facilities. Despite this locational advantage, the large majority of the schools had been flooded. Similarly, more than half of the schools (54\%) met minimum performance standards. In other respects there were serious shortcomings: only $30 \%$ of schools complied with school building codes and only $14 \%$ with guidelines for resilience to hazards. The schools fared better on other criteria, such as access to roads and bridges (55\%), the availability of clean drinking water $(35 \%)$, and sanitary toilet facilities $(45 \%)$.
The emergency preparedness activities data shown in Fig. 6 reveal that a majority of the primary schools $(70 \%)$ did not have any mutual aid plans with nearby schools, $71 \%$ did not have any alternate locations in case of emergency, $86 \%$ lacked available transport to link with other schools and working groups in case of emergency, $91 \%$ did not have plans for alternative ways to deliver lessons (such as home visits) in case of emergency or replace the clinical health services delivered at schools, and $80 \%$ lacked alternative power and water sources. Overall schools only fared well (more than 50\% compliance) on one indicator in this category-the storage of enrollment and educational records, which was achieved by $63 \%$ of the sampled schools. 


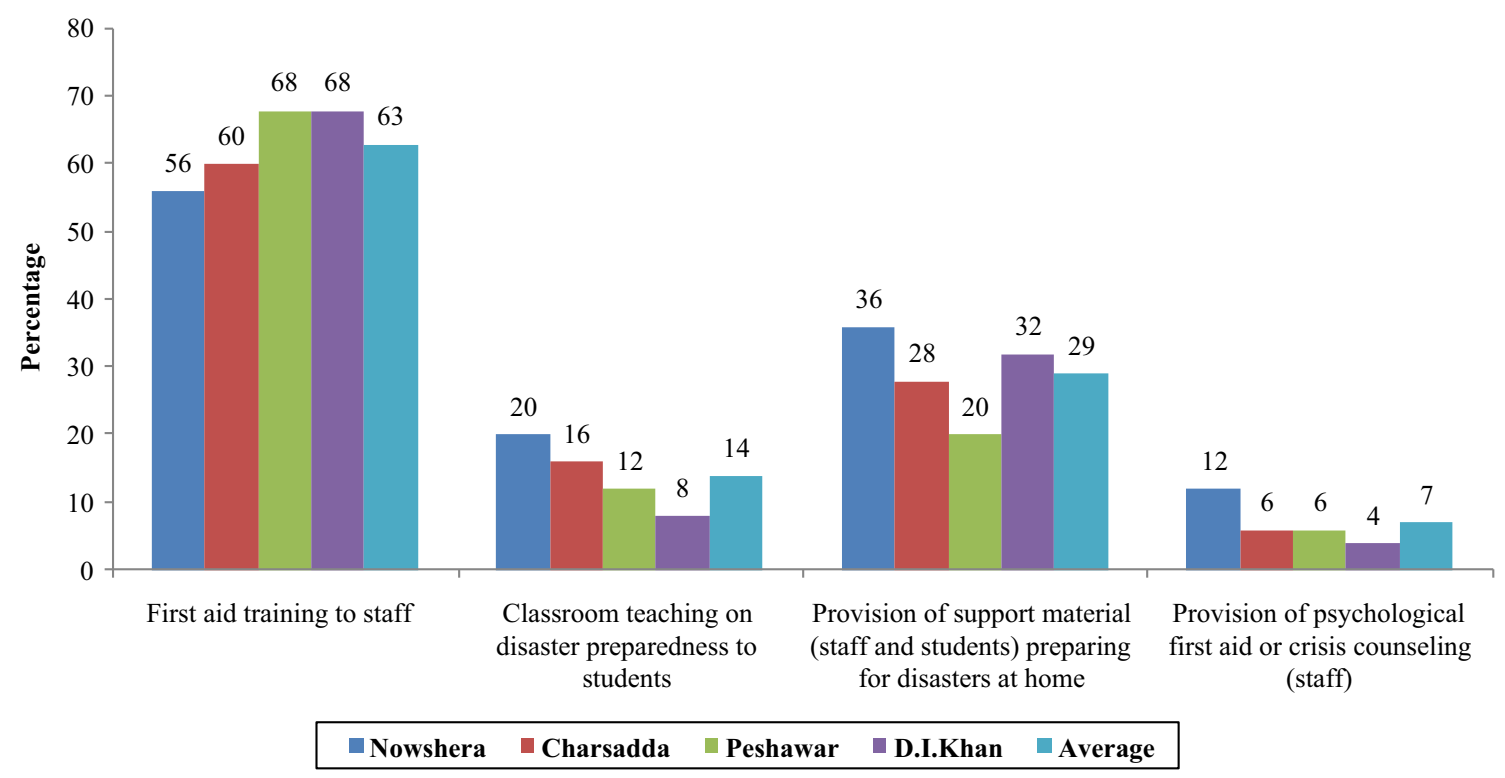

Fig. 7 Hazard education and training preparedness activities of Khyber Pakhtunkhwa's schools, 2010-2017

\subsubsection{Hazard Education and Training}

The data in Fig. 7 show that $63 \%$ of schools had provided first aid training to staff. Dera Ismail Khan and Peshawar fared better in this respect than Nowshara and Charsadda, but only $14 \%$ of the sample had provided basic training on disaster preparedness to students. The majority of schools (71\%) did not provide any material support to students and teaching staff for disaster preparedness at home and only $7 \%$ had made provision for psychological first aid or crisis counseling in the case of an emergency. This is a significant shortcoming that is most likely due to a lack of staff trained in counseling techniques.

\subsection{Discussion}

In Pakistan, floods are the outcome of heavy rainfall during the monsoons particularly in the downstream Indus River basin (Shah et al. 2017), or of rapid snow and glacial melt. Water levels in the Indus basin and its tributaries are higher during the summer season, which is the time of greatest risk to the lives of humans and livestock, standing crops, houses, and other properties (Rahman 2010). The Government of Pakistan (GOP 2013) anticipates that these flood events will occur more frequently and be of greater severity in the future due to a combination of rapid urbanization and climate change (Tariq 2013). The Khyber Pakhtunkhwa Provincial Disaster Management Authority (PDMA-KP 2014) reports that floods are the most harmful type of natural hazard-induced disaster in the region; they cause catastrophic damage to local populations and infrastructure, and particularly to school facilities. Our research indicates that those schools that have experienced flooding have undertaken more preparedness measures than those that have not experienced such catastrophes. This suggests an urgent need to ensure that these latter schools are adequately prepared to deal with flood disaster effectively. Kano et al. (2007) reported that experience of disaster can play an essential role in increasing preparedness efforts to safeguard schools from natural hazard-induced disaster and found a strong linkage between perceived risk and school preparedness.

Our study has revealed that preparedness efforts in terms of emergency planning in schools were low in the four sampled districts (40\%), particularly in Dera Ismail Khan and Peshawar (Fig. 3). This means that it is essential for school management authorities to establish emergency plans and be prepared to deal with disasters, and this can only be achieved through effective planning and corrective actions (FEMA 2010). Primary schools in the four selected districts vary enormously in terms of the emergency preparedness activities that they have carried out, and large variations exist in the measures that they have put in place. Less than half of the schools in our sample have undertaken five out of the seven emergency preparedness measures that we identified (Fig. 3). Yet all of the seven preparedness activities within the emergency planning pillar play a crucial role in ensuring an effective, efficient, and timely emergency response.

The disaster-preparedness literature shows that there are specific social groups, including elderly people and children with disabilities who are disproportionately at risk from flood disaster due to their socioeconomic status and other intrinsic vulnerability factors. These groups require 
specific and focused support from different agencies: governmental and nongovernmental organizations and civic society (schools) (Balbus and Malina 2009; Ronoh et al. 2015a, b). Figure 3 shows that only $23 \%$ of schools have appropriate and inclusive plans for supporting students and teaching staff with disabilities. This implies that children and teachers with disabilities are being neglected, and are particularly vulnerable to extreme weather related disasters such as flooding (AIHW 2009). Site maps and evacuation routes are another essential part of emergency response, since they help staff and students safely leave buildings in a time of panic (Crichton et al. 2009). Yet almost three quarters of schools (74\%) in the sample failed to provide this key information. Similarly, the low level of plans for the continuity of school operations following a disaster (31\% on average) shows that schools in the four districts have not given this issue adequate consideration. This inattention compromises children's continuity in education after a disaster (Peek 2008; GADRRRES 2014). For instance, only $35 \%$ of schools have plans for communication in place-communication is always challenging during an emergency situation, and important for a two-way sharing of information to ensure timely and appropriate responses (Chung et al. 2009).

Analysis of the eight preparation measures used in this study (Fig. 4) also shows a very low degree of preparedness among schools. None of these recommended measures have been adopted by $50 \%$ of schools in the four districts. Five of the measures have only been adopted by $20 \%$ or less of the sampled schools. Most disturbingly, less than $10 \%$ of all schools sampled reported having sufficient equipment and resources, at the same time that less than $15 \%$ reported they provided emergency grab bags or kits and lacked a disaster management handling committee, guidelines, or a school evacuation plan. An average of between 32 and $45 \%$ of schools do have emergency exit signage, emergency equipment in place, and have secured tall and heavy furniture to their walls.

The safe school facilities preparedness pillar plays an important role in ensuring the continuation of school activities during and after flood disaster. Figure 5 shows that the majority (almost two thirds) of schools in the four selected districts are located away from unmitigated hazards in order to protect school facilities from the adverse impacts of flooding. In practice this means that schools are located on sites that are not sloped (so they are free from the risk of landslides), away from electric power lines, and away from rivers and Nullah (intermittent watercourses) of the region. We were surprised to find that the majority of school buildings (54\%) do meet minimum performance standards (local construction materials and design). School authorities must ensure that a school meets minimum design standards, is designed by professionally qualified people, and include plinth protection, columns at strategic places, and appropriate reinforced concrete cement structures. However, the average percentage response to school building codes and standard guidelines was very low in all selected districts. In many respects school administrators are failing to meet these building-code obligations: other school safety measures, such as availability of safe and clean drinking water and sanitary toilet facilities for children and safe access to evacuation facilities were found to be surprisingly inadequate. Much improvement is needed to enable most school authorities from our sample to meet the strategic goals for the education sector set out in the Sendai Framework for Disaster Risk Reduction 2015-2030 (UNISDR 2015). In addition, to physical disaster risk reduction (DRR) measures, social aspects also need to be considered.

The social element includes local community involvement in the rehabilitation and reconstruction process after a disaster to ensure monitoring and further safe construction. The land on which schools are constructed should be registered in the name of government to avoid future disputes. Another component of safe school facilities is planning for the continuation of school activities following an emergency, which is as important as school sites and building design. Figure 6 shows that, with the exception of safe storage of school records, the large majority of the schools have no continuity plans in place. Of particular concern is the low percentage of schools that have mutual aid plans with nearby schools $(30 \%)$, alternate locations for the schools (29\%), the availability of transportation in times of emergency (14\%), plans for alternative ways of teaching following a disaster, such as visiting teachers who deliver lessons (9\%), provision of clinical facilities through schools (9\%), alternative power and water sources (20\%), and linkages between educational institutions and other working groups in order to seek assistance for shelter, health, water, and sanitation (14\%).

The fourth and last preparedness pillar for primary schools concerns hazard awareness and training activities; our findings show an urgent need for more attention and effort (Fig. 7). Although we found that almost two thirds of teachers had received first aid training, schools performed less well on the other three indicators in this category. Less than $15 \%$ of schools provided classroom teaching on disaster preparedness to students, which shows the need to introduce this subject within the core curriculum (Taylor and Moeed 2013; Johnson et al. 2014). There was also a shortage of supportive materials provided by schools to help students and their families prepare for possible disasters within their homes (done by just $29 \%$ of schools). The least covered aspect in terms of hazard education was training in psychological first aid and counseling (provided by only $7 \%$ of schools). As several authors note (AAPC 
Table 1 SWOT analysis of the strengths, weaknesses, opportunities, and threats faced by schools in Khyber Pakhtunkhwa, Pakistan

\begin{tabular}{ll}
\hline Strengths & Weaknesses \\
\hline $\begin{array}{l}\text { More than half (54\%) of school staff are aware of their role and } \\
\text { responsibilities during emergency situations, know how to cope with }\end{array}$ & $\begin{array}{c}\text { Most schools lack emergency communication plans, which will } \\
\text { undermine efforts to respond effectively and in a timely manner to }\end{array}$ \\
$\begin{array}{l}\text { such situations, and to protect human lives and capital assets. This } \\
\text { should result in the mitigation of future unforeseen hazards }\end{array}$ & $\begin{array}{l}\text { any disaster. Only 35\% of schools have established emergency } \\
\text { communication plans, which is a serious weakness }\end{array}$
\end{tabular}

The majority of staff members (55\%) have received essential awareness training about the importance of their continued presence at times of emergency and the support that they should provide at such times

More than $60 \%$ of schools are located away from unmitigated hazards

The majority (54\%) of school buildings are properly designed and meet performance standards

More than half (55\%) of the schools have safe access to roads and/or bridges

More than $60 \%$ of the schools have their enrollment and academic achievement records securely stored to protect them from damage in case of flood

More than $60 \%$ of school staff have received first aid training and could be called upon to provide first-aid to affected students and other staff members
The majority of the schools (77\%) lack plans for students and staff with disabilities, making them more vulnerable to natural hazards, which is a weakness that should be addressed

A large number of schools (69\%) have not established plans for continuing school operations after a disaster

A high percentage of schools (74\%) lack a mapping system to identify evacuation routes

A large majority $(86 \%)$ of the schools do not have an committee for handling emergencies

$80 \%$ of the schools do not have evacuation plans, which is a visible weakness

The large majority (87\%) of schools have not established disaster preparedness guidelines

The majority of the respondents from the selected schools (71\%) have not received capacity building training on safety and security, which is an evident weakness

A high percentage of schools (70\%) do not adhere to building codes

The majority of the schools $(91 \%)$ do not have plans for alternate means of instruction, such as visiting teachers delivering lessons

The majority (70\%) of the schools lack access to transport facilities in case of emergency

A large majority of schools (80\%) lack alternate sources for power and water

A large majority of schools ( $>90 \%$ ) have not provided training on psychological first aid and crisis counseling to their staff
Opportunities

About $40 \%$ of the selected schools in the four districts have developed an emergency plan which could be used as templates for the remaining $60 \%$ of schools to make plans

$45 \%$ of the schools have adopted DRR measures in terms of fixing heavy items such as cupboards and furniture to the walls to prevent them from injuring people if they fell. It would be relatively simple and cost free for the remaining 55\% of schools to apply the same measures

There is an opportunity for the schools who have not got first aid training to avail themselves of the services of the staff from other schools who have received such training

$29 \%$ of staff and students have been provided with advice on how to be prepared and cope with disasters at home. This knowledge can be imparted to other schools and areas thereby enhancing community preparedness

\section{Threats}

Only $32 \%$ of school facilities have emergency exits with signage. The remaining $68 \%$ lack such facilities, which increase students' vulnerability in case of the need for evacuation

Only 34\% of schools have sufficient equipment for handling an emergency or disaster. The majority of the schools are not equipped and are exposed to floods and lack coping mechanisms

Only $14 \%$ schools can provide their students with grab bags and kits and the nonavailability in the rest of the schools is a potential threat

Only $9 \%$ of schools have enough equipment and resources to deal with emergencies, with the remaining $90+\%$ exposed to risks and unable to cope with emergencies

Very few schools (14\%) have guidelines for multihazard resilient construction that are easily understood and widely disseminated. More than $85 \%$ of schools lack such guidelines

Only $35 \%$ of schools have access to clean, potable water; the remaining schools are at risk of a heightened waterborne disease threat

Almost half of the schools (45\%) lack adequate sanitary and sanitation facilities, which can result in an outbreak of diseases especially after a flood incident

Only $30 \%$ of schools have mutual aid plans, or alternate sites to ensure the continuity of students' education. The lack of such plans in the remaining $70 \%$ of schools is a critical threat to educational continuity

Less than $10 \%$ of the schools have access to clinical health services. During an emergency, the lack of availability of such services can pose a threat to human lives

Only $14 \%$ of the schools have given lessons to their students on disaster preparedness 
2008; MacNeil and Topping 2009; Elangovan and Kasi 2015; Mutch 2015) it is important that school teachers, as respected members of their communities, are able to provide emotional and cognitive support to their students during and after a traumatic emergency situation.

\subsection{SWOT Analysis}

Given existing school structures, their locations, and their vulnerability to floods, we carried out a SWOT ${ }^{5}$ analysis that uses each of the indicators from the four pillars to assess the extent of school vulnerability to flood hazard. This analysis allows us to gauge the preparedness level (strengths and weaknesses) and challenges (opportunities and threats) to which schools are exposed. Many steps have already been taken by regional governments, humanitarian organizations, and school administrations (strengths), but many weaknesses still exist. The opportunities for improving the flood-preparedness situation and constraints in so doing (threats) are also summarized (Table 1).

There is much existing knowledge and technology that can be applied to lowering risks and vulnerability within schools and many different ways to promote safety in schools. For example, educating school children about how to reduce risks within their environment and the transmission of such information to the entire family can contribute to safer communities. One of the main strengths highlighted in Table 1 is that more than half of school staff are aware of their roles and responsibilities in times of emergency. This strength is also an opportunity for the remaining schools to adopt the same measures. But the findings also reveal that a majority of schools are not adequately prepared for flood disasters as they lack evacuation plans, disaster preparedness guidelines, emergency communication plans, mapping systems, committees for handling emergencies, emergency transportation facilities, alternate sources for power and water, plans for disabled students or for continuing school operations after a disaster, and properly trained staff who can provide psychological first aid and crisis counseling. These are weaknesses that also constitute threats in times of emergency.

Table 1 shows that a significant number of the schools do have an emergency plan, have adopted DRR measures, have provided staff with first aid training and training on key messages for disaster preparedness at home. The existence of such experience and knowledge provides an opportunity for other schools in the same area, which are

\footnotetext{
${ }^{5}$ SWOT analysis is "a simple but powerful tool for sizing up an organization's resource capabilities and deficiencies, its market opportunities, and the external threats to its future" (Thompson et al. 2007, p. 97). The acronym SWOT stands for strengths, weakness, opportunities, and threats. SWOT analysis is also referred to as SWOT matrix.
}

more vulnerable through lacking these safeguards, to learn from and replicate these examples as it would be relatively easy to tap into the skills and services of trained staff from nearby schools. We adopted a benchmark of $40 \%$ compliance to judge the existence of "threats" in Table 1. It is notable that in almost two-thirds of the thirty four disaster preparedness indicators identified in Figs. 3, 4, 5, 6 and 7, the average compliance rate is less than $40 \%$, indicating a very high level of vulnerability. This is particularly notably in terms of disaster preparedness (Fig. 4) and planning for the continuation of schools after a disaster (Fig. 6) where only one of the eight performance indicators is attained by $40 \%$ of schools.

Concerns about school safety are starting to receive far more international recognition, particularly in Asia, where numerous conferences and declarations have drawn attention to this pressing issue. In addition, some national commitments emerged. The Economic Cooperation Organization (ECO) meetings on Disaster Management (Islamabad, October 2007) highlighted the importance of school safety (PFF 2018). It is imperative that the directorate of the Khyber Pakhtunkhwa elementary and secondary education works closely with schools and communities in flood-prone areas in order to strengthen flood emergency preparedness in schools. Positive results can be attained by installing adequate physical protection, raising awareness of the flood threat to schools, and improving knowledge and skills through capacity-building programs.

\section{Conclusion}

Flood disasters occur with depressing regularity in schools in Khyber Pakhtunkhwa Province so it is important that advanced standardized procedures, strategies, and plans are in place to deal with them. This study assessed the preparedness of Khyber Pakhtunkhwa's schools and their ability to safeguard their students and teachers in case of flood emergency. It revealed large variations in the level and degree of emergency preparedness activities undertaken by primary schools, both between the four study districts and in terms of the actual activities. Overall it showed that the majority of schools are underprepared to deal with such events effectively. It also exposed the fact that the majority of school authority heads are unaware of, and lack clarity in, which preparedness activities are essential and expected to be undertaken. The study highlights some areas in which there is a relatively high level of compliance with preparedness indicators, but many more in which the vast majority of schools are underprepared. In these cases significant improvements are required in order to strengthen emergency preparedness efforts. 
DRR measures, such as the construction of schools at safer locations on sites that are free from the risk of landslide and falling power lines, and that conform with building and performance standards to avoid damage, are often disregarded. Other than these DRR measures, consideration should also be given to social aspects. These include involving the local community in rehabilitation and reconstruction in order to ensure monitoring and further safe construction.

In summary, this study showed the pressing need to overcome the lack of flood preparedness in Khyber Pakhtunkhwa's schools. Designing school safety policies should be a priority component of national and local government plans on emergency preparedness and mitigation. The government of Khyber Pakhtunkhwa should build partnerships with other stakeholders including NGOs to design and implement national/provincial school emergency preparedness programs and allocate sufficient funds to implement structural and nonstructural mitigation measures.

Acknowledgements This study was part of Ph.D. research at the College of Humanities and Development Studies (COHD), China Agricultural University, Beijing, China. The research project was made possible by the sponsorship of the Chinese Scholarship Council (CSC). We are extremely thankful to the College of Humanities and Development (COHD) Studies, as well as the Directorate of Elementary and Secondary Education (E\&SE) Khyber Pakhtunkhwa and school representatives, for their effective support and coordination in organizing and conducting successful interviews. Further, we would like to thank our survey team members in conducting interviews during August and September 2017. We are very thankful to Nicholas Parrott for his contribution to the proofreading and editing of this manuscript.

Open Access This article is distributed under the terms of the Creative Commons Attribution 4.0 International License (http://crea tivecommons.org/licenses/by/4.0/), which permits unrestricted use, distribution, and reproduction in any medium, provided you give appropriate credit to the original author(s) and the source, provide a link to the Creative Commons license, and indicate if changes were made.

\section{References}

AAPC (American Academy of Pediatrics, Council on School Health). 2008. Disaster planning for schools. Pediatrics 122(4): 895-901.

ADB (Asian Development Bank), and WB (World Bank). 2010. Pakistan floods 2010: Preliminary damages and needs assessment. Islamabad: Asian Development Bank and World Bank. https://siteresources.worldbank.org/PAKISTANEXTN/ Resources/293051-1264873659180/6750579-1291656195263/ PakistanFloodsDNA_December2010.pdf. Accessed 3 Dec 2017.

ADPC (Asian Disaster Preparedness Center). 2010. Working paper: Culture of safety in schools-mandatory or by choice. https:// www.preventionweb.net/go/17583. Accessed 28 June 2017.

AIHW (Australian Institute of Health and Welfare). 2009. A picture of Australia's children 2009. Canberra: AIHW.
Alba, D.J., and R.K. Gable. 2012. School safety planning: Barriers to implementation perceived by district leadership and first responders. Paper Presented at the 43rd Annual Meeting of the Northeastern Educational Research Association, 19 October 2012, Rocky Hill, CT, USA.

Awofisayo, A., S. Ibbotson, G.E. Smith, K. Janmohamed, H. Mohamed, and B. Olowokure. 2013. Challenges and lessons learned from implementing a risk-based approach to school advice and closure during the containment phase of the 2009 influenza pandemic in the West Midlands, England. Public Health 127(7): 637-643.

Balbus, J.M., and C. Malina. 2009. Identifying vulnerable subpopulations for climate change health effects in the United States. Journal of Occupational and Environmental Medicine 51(1): 33-37.

Brown, R.L., and H. Holmes.1986. The use of a factor-analytic procedure for assessing the validity of an employee safety climate model. Accident Analysis \& Prevention 18(6): 455-470.

Brown, L., H. Boon, and P. Pagliano. 2014. Emergency planning for students with disabilities: A survey of Australian schools. Australian Journal of Emergency Management 29(4): 45-49.

Chung, S., J. Danielson, and M. Shannon. 2009. School-based emergency preparedness: A national analysis and recommended protocol. Rockville, MD: Agency for Healthcare Research and Quality.

Cox, S., and T. Cox. 1991. The structure of employee attitudes to safety: A European example. Work \& Stress 5(2): 93-106.

Coyle, I.R., S.D. Sleeman, and N. Adams. 1995. Safety climate. Journal of Safety Research 26(4): 247-254.

Crichton, M.T., C.G. Ramsay, and T. Kelly. 2009. Enhancing organizational resilience through emergency planning: Learnings from cross-sectoral lessons. Journal of Contingencies and Crisis Management 17(1): 24-37.

Dedobbeleer, N., and F. Béland. 1991. A safety climate measure for construction sites. Journal of Safety Research 22(2): 97-103.

Elangovan, A.R., and S. Kasi. 2015. Psychosocial disaster preparedness for school children by teachers. International Journal of Disaster Risk Reduction 12: 119-124.

Fahad, S., and J. Wang. 2018a. Evaluation of Pakistani farmers' willingness to pay for crop insurance using contingent valuation method: The case of Khyber Pakhtunkhwa province. Land Use Policy 72: 570-577.

Fahad. S., J. Wang, G. Hu, H. Wang, X.Y., Yang, A.A. Shah, N.T.L., Huong, and A. Bilal. 2018b. Empirical analysis of factors influencing farmers crop insurance decisions in Pakistan: Evidence from Khyber Pakhtunkhwa province. Land Use Policy 75: 459-467.

FEMA (Federal Emergency Management Agency). 2010. Bringing youth preparedness education to the forefront: A literature review and recommendations. http://www.citizen/corps.gov. Accessed 18 July 2011.

GADRRRES (Global Alliance for Disaster Risk Reduction and Resilience in the Education Sector). 2014. Comprehensive school safety. Geneva, Switzerland: United Nations International Strategy for Disaster Reduction. http://preventionweb.net/go/ 31059. Accessed 3 July 2017.

Geller, E.S. 1994. Ten principles for achieving a total safety culture. Professional Safety 39(9): 18.

GOP (Government of Pakistan). 2013. National disaster risk reduction policy-2013. Islamabad: National Disaster Management Authority, Ministry of Climate Change.

Graham, J., S. Shirm, R. Liggin, M.E. Aitken, and R. Dick. 2006. Mass-casualty events at schools: A national preparedness survey. Pediatrics 117(1): e8-e15.

Guldenmund, F.W. 2000. The nature of safety culture: A review of theory and research. Safety Science 34(1): 215-257. 
Hosseini, M., and Y.O. Izadkhah. 2006. Earthquake disaster risk management planning in schools. Disaster Prevention and Management: An International Journal 15(4): 649-661.

Johnson, V.A., K.R. Ronan, D.M. Johnston, and R. Peace. 2014. Evaluations of disaster education programs for children: A methodological review. International Journal of Disaster Risk Reduction 9: 107-123.

Johnston, D., R. Tarrant, K. Tipler, E. Lambie, M. Crawford, V. Johnson, J. Becker, and K. Ronan. 2016. Towards tsunami-safer schools in the Wellington region of New Zealand: Evaluating drills and awareness programs. Australian Journal of Emergency Management 31(3): 59-66.

Kano, M., and L.B. Bourque. 2007. Experiences with and preparedness for emergencies and disasters among public schools in California. NASSP Bulletin 91(3): 201-218.

Kano, M., M. Ramirez, W.J. Ybarra, G. Frias, and L.B. Bourque. 2007. Are schools prepared for emergencies? A baseline assessment of emergency preparedness at school sites in three Los Angeles county school districts. Education and Urban Society 39(3): 399-422.

Khan, A.N., and A. Ali. 2014. Implication of floods-2010 on education sector in Pakistan. In Disaster recovery: Used or misused development opportunity, ed. R. Shaw, 117-133. Tokyo: Springer.

Lee, T.R. 1996. Perceptions, attitudes and behaviour: The vital elements of a safety culture. Health and Safety 10: 1-15.

Lutness, J. 1987. Measuring up: Assessing safety with climate surveys. Occupational Health \& Safety 56(2): 20.

MacNeil, W., and K. Topping. 2009. Crisis management in schools: Evidence based. The Journal of Educational Enquiry 7(1): 64-94.

Mamogale, H.M. 2011. Assessing disaster preparedness of learners and educators in Soshanguve North schools. Bloemfontein, South Africa: The Disaster Management Training and Education Centre for Africa, the University of the Free State. https://www. ufs.ac.za/docs/librariesprovider22/disaster-management-train ing-and-education-centre-for-africa-(dimtec)-documents/disserta tions/2291.pdf?sfvrsn=2. Accessed 3 July 2017.

Masten, A.S., A.J. Narayan, W.K. Silverman, and J.D. Osofsky. 2015. Children in war and disaster. In Handbook of child psychology and developmental science, ed. R.M. Lerner, M.H. Bornstein, and T. Leventhal, 704-745. New York: Wiley.

McBride, E. 2017. Establishing a baseline of school safety practices using rapid pro real-time SMS technology in Khyber Pakhtunkhwa. Islamabad: Education Section UNICEF Pakistan Country Office.

Momani, N.M, and A. Salmi. 2012. Preparedness of schools in the Province of Jeddah to deal with earthquakes risks. Disaster Prevention and Management: An International Journal 21(4): 463-473.

Mutch, C. 2015. The role of schools in disaster settings: Learning from the 2010-2011 New Zealand earthquakes. International Journal of Educational Development 41: 283-291.

Newman, E., B. Pfefferbaum, N. Kirlic, R. Tett, S. Nelson, and B. Liles. 2014. Meta-analytic review of psychological interventions for children survivors of natural and man-made disasters. Current Psychiatry Reports 16(9): 462.

Ostrom, L., C. Wilhelmsen, and B. Kaplan. 1993. Assessing safety culture. Nuclear Safety 34(2): 163-172.

PDMA-KP (Provincial Disaster Management Authority-Khyber Pakhtunkhwa). 2014. District disaster risk management plan Nowshera. DRM \& CCA Strategic Unit, PDMA Khyber Pakhtunkhwa. http://www.pdma.gov.pk. Accessed 11 July 2017.

Peek, L. 2008. Children and disasters: Understanding vulnerability, developing capacities, and promoting resilience-An introduction. Children Youth and Environments 18(1): 1-29.
PFF (Pakistan FisherFolk Forum). 2018. Resilent, informed and safer schools and communities project-Sindh Province-Six Districts: Khairpur, Sukkur, Mirpurkhas, Sanghar, Tando Allahyar and Umerkot. Karachi, Pakistan: UNICEF Pakistan. http://pff. org.pk/unicef-school-safety/. Accessed 23 Sept 2017.

Rahman, A.U. 2010. Disaster risk management: Flood perspective. Saarbrücken: VDM Verlag Publishing.

Ramirez, M., K. Kubicek, C. Peek-Asa, and M. Wong. 2009. Accountability and assessment of emergency drill performance at schools. Family \& Community Health 32(2): 105-114.

Ronan, K., and D. Johnston. 2005. Promoting community resilience in disasters: The role for schools, youth, and families. New York: Springer.

Ronoh, S., J.C. Gaillard, and J. Marlowe. 2015a. Children with disabilities and disaster risk reduction: A review. International Journal of Disaster Risk Science 6(1): 38-48.

Ronoh, S., J.C. Gaillard, and J. Marlowe. 2015b. Children with disabilities and disaster preparedness: A case study of Christchurch. Kōtuitui: New Zealand Journal of Social Sciences Online 10(2): 91-102.

Sakurai, A., and R. Shaw. 2015. Implications of 3.11 for disaster education and education for sustainable development in Japan. In Educating for sustainability in Japan: Fostering resilient communities after the triple disaster, ed. J. Singer, T. Gannon, F. Noguchi, and Y. Mochizuki, 36-51. London: Taylor and Francis.

Shah, A.A., J. Ye, M. Abid, and R. Ullah. 2017. Determinants of flood risk mitigation strategies at household level: A case of Khyber Pakhtunkhwa (KP) province, Pakistan. Natural Hazards 88(1): 415-430.

Shah, A.A., J. Ye, M. Abid, J. Khan, and S.M. Amir. 2018. Flood hazards: Household vulnerability and resilience in disaster-prone districts of Khyber Pakhtunkhwa province, Pakistan. Natural Hazards. https://doi.org/10.1007/s11069-018-3293-0.

Shaw, R, Y. Takeuchi, Q.R, Gwee, and K. Shiwaku. 2011. Disaster education: An introduction. In Disaster education, ed. R. Shaw, 1-22. Bingley: Emerald Group Publishing.

Shiwaku, K., Y. Ueda, Y. Oikawa, and R. Shaw. 2016. School disaster resilience assessment: An assessment tool. In Disaster resilience of education systems: Experiences from Japan, ed. K. Shiwaku, A. Sakurai, and R. Shaw, 105-130. Tokyo: Springer.

Tariq, M.A.R. 2013. Risk-based flood zoning employing expected annual damages: The Chenab River case study. Stochastic Environmental Research and Risk Assessment 27(8): 1957-1966.

Taylor, M., and A. Moeed. 2013. The 2010 Canterbury Earthquake: Curriculum shockwaves. International Research in Geographical and Environmental Education 22(1): 57-70.

Thompson, A.A., A.J. Strickland, and J.E. Gamble. 2007. Crafting and executing strategy-Concepts and cases, 15 edn. New York: McGrawHill/Irwin.

Tipler, K., R. Tarrant, D. Johnston, and K. Tuffin. 2017. Are you ready? Emergency preparedness in New Zealand schools. International Journal of Disaster Risk Reduction 25: 324-333.

UNESCO (United Nations Educational, Scientific and Cultural Organisation). 2012. School safety action plan: Plan of action for safe school and educational buildings in Khyber Pakhtunkwa. http://unesco.org.pk/documents/2013/ndm_School-SafetyAction-Plan.pdf. Accessed 7 Nov 2017.

UNISDR (United Nations International Strategy for Disaster Reduction). 2007. Towards a culture of prevention: Disaster risk reduction begins at school-Good practices and lessons learned, ed. R.A. Valency, and J. Lazarte. Geneva: UNISDR. https:// www.unisdr.org/files/761_education-good-practices.pdf. Accessed 16 May 2018. 
UNISDR (United Nations International Strategy for Disaster Reduction). 2015. Sendai framework for disaster risk reduction 20152030. Geneva: UNISDR.

US Government Accountability Office. 2007. Most School Districts Have Developed Emergency Management Plans, but Would Benefit from Additional Federal Guidance (GAO-07-609). Washington, DC: Government Accountability Office.

WHO (World Health Organization). 2011. Disaster risk management for health fact sheets: Disaster risk management for health: Child health. Geneva: WHO.

Williamson, A.M., A.-M., Feyer, D. Cairns, and D. Biancotti. 1997. The development of a measure of safety climate: The role of safety perceptions and attitudes. Safety Science 25(1-3): 15-27.
Wisner, B. 2006. Let our children teach us: A review of the role of education and knowledge in disaster risk reduction. Bangalore: Books for Change on behalf of UNISDR and UNESCO.

Zantal-Wiener, K., and T.J. Horwood. 2010. Logic modeling as a tool to prepare to evaluate disaster and emergency preparedness, response, and recovery in schools. New Directions for Evaluation 2010(126): 51-64.

Zohar, D. 1980. Climate in industrial organizations: Theoretical and applied implications. Journal of Applied Psychology 65(1): 96. 